\title{
The self's choice: Priming attentional focus on bodily self promotes loss frequency bias
}

\author{
Valeria Sebri ${ }^{1,2}$ (D) Stefano Triberti ${ }^{1,2} \cdot$ Gabriella Pravettoni $^{1,2}$ \\ Accepted: 20 January 2021 / Published online: 5 February 2021 \\ (C) The Author(s) 2021
}

\begin{abstract}
When attention is focused on self representation(s), the ability to evaluate one's internal sensations is enhanced, according to previous research by Ainley and colleagues (Consciousness and Cognition, 22(4), 1231-1238, 2013). Selfrepresentations are usually distinguished between bodily and narrative. Both bodily and narrative representations improve decision-making processes, in that the consideration of alternatives is informed by sensations experienced deep inside the body (e.g., anxiety) as suggest by the literature (Noël, Brevers \& Bechara in Frontiers in Psychiatry, 4, 179, 2013). The objective of the present study is to analyze the decision-making process in multiple conditions of stimulated self-representations. Participants played the Iowa Gambling Task three times (a baseline without stimuli and two randomly ordered stimulations to prime bodily and narrative self-representations). While no significant differences emerged regarding advantageous choices, participants showed loss frequency bias in the condition with bodily-self representation priming. Two interpretations are proposed: bodily-self focus acted as a distractor diminishing participants' commitment to long term outcomes or enhanced interoception promoted aversion to losses. Directions are given for future research and clinical implications.
\end{abstract}

Keywords Decision-making $\cdot$ Bodily self $\cdot$ Narrative self $\cdot$ Iowa gambling task $\cdot$ Self $\cdot$ Loss aversion

\section{Introduction}

Over the years, the self has been conceptualized in many ways in psychology, neuroscience, and philosophy (Strohminger, Knobe, $\&$ Newman, 2017). The self-concept is a system of cognitive and affective structures ("schemas") that lends coherence and structure to one's significant experiences (Christoff, Legrand, Cosmelli, \& Thompson, 2011). In particular, the self acts to maintain a homeostasis between an individual and his or her social context promoting subjective well-being (Sui \& Humphreys, 2015). In other words, self-representations are relevant regulators of behaviors (Markus \& Kunda, 1986) and act as an integrative hub linking together information and cognitive

Valeria Sebri

valeria.sebri@unimi.it

1 Department of Oncology and Hemato-Oncology, University of Milan, via Festa del Perdono 7, 20122 Milan, Italy

2 Applied Research Division for Cognitive and Psychological Science, IEO European Institute of Oncology IRCCS, via Giuseppe Ripamonti 435, 20141 Milan, Italy processing to direct actions, pursue goals, and regulate emotions (Mancha \& Yoder, 2015; Markus, Smith, \& Moreland, 1985; Riesmeyer, Hauswald \& Mergen, 2019). Studies from social psychology usually refer to the self as one's representations of characteristics, personality traits, social preferences, and values (Choi, Cho, Seo \& Bechtoldt, 2018; Thagard \& Wood, 2015). According to this view, an individual could have multiple and context-dependent self-representations expressed in an interrelated memory network (McConnell, Shoda \& Skulborstad, 2012). These multiple selves are related to group belonging (e.g., "social identity") (Tajfel, 1974) as well as self-perception and aspirations (e.g., actual, ought, and ideal self) (Higgins, 1987) and are integrated within long-term memory, yet they are fluid and could change due to external stimuli (e.g., contexts) (McConnell et al., 2012). Moreover, multiple selves affect decision making (DM) and behaviors, in that people make choices relying on thoughts and convictions integrated in their past, current, or ideal/future self (Jamison \& Wegener, 2010).

In cognitive science, the idea of multiple selves relates to another kind of differentiation, namely that between the body, as the source of perceptual/procedural knowledge ("what we feel"), and declarative memory ("what we know") about ourselves (Roelofsma \& Kurt, 2013). This echoes 
James' original distinction between bodily and narrative selves (James, 2011). Firstly, the bodily self is "an integrated system characterized by matching of sensory-motor information", not detached from experience (Legrand, 2006, p. 111). Bodily self relates to an idea of embodied self or the body as an expression of implicit knowledge about body-effectors and actions (Frassinetti, Ferri, Maini, Benassi \& Gallese, 2011). Consistently, experimental evidence shows that brain areas reflect appearance and location of the body in terms of self-identification or body-ownership (e.g., which limbs are part of my body), self-location (e.g., where my body is in the space), and first-person perspective (one's subjective perception of the world) (Blanke, 2012). For example, Salomon and colleagues (2017) reported that the integration of bodily stimuli within the peri-personal space highlighted the bodily self-consciousness, especially in terms of both selfidentification (the experience of the self in the own body) and self-location (the experience of the self in a specific location in the space). Second, the narrative or autobiographical self is related to stored knowledge about experience and/ or anticipated ideas about the future, referring to historical aspects of one's own life (Sui \& Humphreys, 2015). The narrative self emerges by retrieving memories about one's biographical information (ranging from simple identity-relevant facts, such as date and place of birth, to life events as high school graduation) and personality traits (e.g., being honest) (Araujo, Kaplan, Damasio \& Damasio, 2015). Additionally, it could be strongly affected by specific traumatic experiences, such as illness (Sebri, Triberti \& Pravettoni, 2020a; Triberti, Gorini, Savioni, Sebri \& Pravettoni, 2019). The self exchanges information with the episodic memory system to produce the sensory-perceptual-affective reconstruction of experiences and sustains long-term self-representations (Singer, Blagov, Berry \& Oost, 2013). This memory system model is based on retrieving autobiographical narratives by memory storage thanks to "self-event connections" which integrate specific episodes into the subjective life-story (Merrill, Waters \& Fivush, 2016). Moreover, the narrative self and its related memories are relevant for social interactions. Dominey and colleagues (2017) showed that the narrative history of shared social interaction with others is a central component of the self. The authors evidenced that the ability of a narrative companion (e.g., a robot) can accompany individuals with impaired narrative memory in the recording and sharing of memories with a new level of alternate and augmentative communication that helps to maintain positive social interactions. Historical and biographical events indeed allow individuals to generate an account of their ongoing body states, directly influenced by interoceptive signals from body changes (e.g., the perception of thirst and hunger) as well as exteroceptive signals from the context (e.g., external pressure on the body) at a specific moment in time (Araujo et al., 2015).
These two facets of the self, narrative and bodily, are not independent but in a continuous relationship with each other and with the external environment. Consistently, Damasio (2010) proposed a taxonomy based on the grounding of the narrative self in bodily self-processes through autobiographical memories. This way, bodily and narrative self could be defined as a hub to process information through the association between perception, memory, and decision-making (DM) (Sui \& Humphreys, 2015). These traditional multiple interactions are possible thanks to exteroception (outwardly- directed five senses), interoception (awareness of inner states such as thirst, hunger, heartbeat), and proprioception (perception of one's own position and movement) processes which are helpful to explore individual self-related information and cognitive-affective processing (Di Lernia, Cipresso, Pedroli \& Riva, 2018; Sebri, Savioni, Triberti, Mazzocco \& Pravettoni, 2019; Sebri et al., 2020b). This way, the ability to focus attention on oneself is not just the awareness of one's own mental and bodily states but also a fundamental tool to plan and implement actions (Bermúdez, 2011). For example, Piff and colleagues (2015) reported that feelings of a small self (i.e., a diminished sense of the own self, such as one's goals and interests to be less significant compared with a greater good) promote ethical decision making in terms of generosity and pro-sociality behaviors.

This is consistent with the "perceptual accuracy hypothesis" (Silvia \& Gendolla, 2001) that explains how interoceptive and exteroceptive self-focused attention increase the ability to judge somatic and cognitive aspects of the self. According to the study of Ainley and colleagues (2013), self-focused attention could be increased by the mere presence of a mirror or by looking at a picture of one's face. Specifically, they contrasted a condition in which participants looked at their face (the bodily self-stimulus) with another in which they looked at self-relevant words (the narrative self-stimulus); results show that both self-focus conditions were equally effective to improve accuracy in a heartbeat awareness task. Similarly, Northoff (2007) evidenced that the more the stimulus is correlated to individuals' sense of belongingness, the more strongly it can be associated with the self. The authors highlighted that self-related stimuli in memory task require stronger involvement of own narrative encoding and retrieval induced by one's face. On this basis, it is paramount to understand how self-representations enhance by bodily and narrative selves' stimuli affect cognitive processes.

\section{Does Self-Focused Attention Influence Decision Making?}

The inner self-perception is associated with decision-making processes, as showed by Werner and colleagues (2009). The authors demonstrated that people with high interoceptive ability performed better in DM tasks such as the Iowa Gambling 
Task (IGT) (Bechara, 2008), which is a tool to assess DM processes. In this task, participants choose cards from four different decks (A, B, C, D) to maximize gains and minimize losses. Two decks (A and B) offer $\$ 100$ reward, on average, and large punishments and the other two $(\mathrm{C}$ and $\mathrm{D})$ offer $\$ 50$ rewards, on average, and small punishments. Generally, participants learn how to collect money as a functional process of DM in healthy people (learning effect) (Bechara et al., 1997). Consistently, bodily feedback theories (Price \& HarmonJones, 2015) showed that anticipatory bodily signals can influence decisions by giving access to relevant internal sensations in the evaluation of alternatives. This is in agreement with Dunn and colleagues (2010) who demonstrated that intuitive DM processes depend on whether anticipated bodily signals lead to advantageous or disadvantageous decisions. Moreover, Baumeister (1984) sustained that dispositional self-consciousness and attention to internal sensations can influence cognitive functions during a task, possibly even impairing performance due to distraction. However, consistent evidence about the relation between self-focused attention and decision-making is scarce; Sokol-Hessner and colleagues (2015) showed that individuals with higher interoceptive abilities showed increases in loss aversion. Loss aversion is the tendency to overweight losses compared with equivalentsized gains as a central element of prospect theory and it explains deviations from the expected outcomes ( $\mathrm{Gal} \&$ Rucker, 2018; Tversky \& Kahneman, 1992). On the contrary, people with affect perception disorders such as alexithymia (Sokol-Hessner \& Rutledge, 2019) and overall amygdala damages (De Martino, Camerer \& Adolphs, 2010) showed lower loss aversion.

In general, there are two ways the self can impact DM: first, as inner information (sensorial, interoceptive factors) it improves the assessment of alternatives, by making the decision-maker more aware of his or her own "gut" responses; secondly, in terms of the narrative self, it is a reference point for values and motivations to orient important decisions. In the following study, we will investigate the first issue, specifically the effect on decision-making of two experimental manipulations of self-focus, namely bodily and narrative (Ainley et al., 2013).

It is possible to state fundamental hypotheses for the present work:

(Hp1) participants will perform more advantageous decisions in the IGT when the bodily or the narrative self is primed than in a baseline condition with no self-priming. Indeed, autobiographical memories and emotions can influence how we make decisions; secondarily, observing one's own image increases the ability to make decisions, for example in the context of moral choices (Ploner \& Regner, 2013);
(Hp2) participants will show loss frequency bias in the Iowa Gambling Task when the bodily or the Narrative Self is primed compared with baseline condition with no self-priming. Loss frequency bias is the tendency to gamble with decks with infrequent but heavier punishments (Cassotti et al., 2014). There is a debate in the literature on whether such patterns of choice should be considered advantageous or disadvantageous (Cassotti et al., 2014) as participants are avoiding to be punished often. Such pattern of choice emerged in children and adolescents compared with adults (Cassotti et al., 2014), as well as in older participants (Beitz, Salthouse, \& Davis, 2014), and in pathological conditions such as schizophrenia, where it has been associated with impairments in working memory (Brown et al., 2015). It is possible that loss frequency bias will emerge in participants in experimental conditions if self-focus is distracting (Baumeister, 1984) and will make participants more likely to forget about recent outcomes, less likely to concentrate to inhibit intuitive strategies, and therefore less likely to consider long term outcomes. Moreover, previous studies showed that the focused attention on inner processes predicts aversion to losses in monetary choices tasks (a phenomenon consistent with loss frequency bias in the Iowa Gambling Task) because the heightened subjective intensity of choice-relevant emotional signals magnifies the weight placed on losses (Sokol-Hessner et al., 2015);

(Hp3) sex differences will influence results in decision-making. Many studies show that sex influences $\mathrm{DM}$ but the debate is still ongoing. In general, the literature showed that females have higher levels of loss aversion and invest less in risky decisions, while males are less conservative, and more vulnerable to risk-taking (Charness \& Gneezy, 2012). Moreover, as the present study aims to manipulate self-focused attention to influence decisions, it may be important that females are more sensitive to social context and more convinced that negative possible selves might develop (Stevenson \& Clegg, 2011). Other research, instead, affirms that there is no difference between males and females in the quality of DM, in contrast with the earlier literature. Possible differences, in fact, could be related to information access, personality types, and experience commonly associated with genders rather than to sex (Johnson \& Powell, 1994);

(Hp4) there will be a growing improvement of total profit and a decrease of the time over the conditions as a learning effect. The pressure of touch could become also fainter over time as a result of more confidence and/or ability in the IGT due to exercise (Stanton, Liening \& Schultheiss, 2011). 


\section{Methods}

\section{Ethics Statement}

At the beginning of the experimental study, participants signed a written consent; they were volunteers, not compensated (no incentive reward was given), and free to withdraw from the study at any time without the need to justify their choice.

\section{Participants}

Researchers proposed the study participation by asking people aged older than 18 , promoting mouth-to-mouth communication, and posting a brief announcement on online social networks, such as Facebook pages. People were welcomed to share the invitation to participate in the research study providing contacts of researchers (e.g., telephone number and email address) following a snowball sampling technique to increase the number of participants. Young adults characterize the majority of the total sample (25-36 years) (Shook et al., 2019), individuals with a graduate degree and white-collar employers (see Table 1).

We ran a priori power analysis to assess the risk of incurring Type II errors given the expected medium effect size. Analyses were run with GPower (Faul, Erdfelder, Lang, \& Buchner, 2007), with power (1-b) set at .80 and an equal to .05 , one-tailed. Analyses indicated 28 participants as the total sample size necessary. Participants were 30 adults (16 females) and the mean age was $28,83(\mathrm{SD}=5,65)$. Only one

Table 1 Socio-demographic characteristics of the current sample

Total sample $(N=30)$

n $\%$

\begin{tabular}{lll}
\hline Gender & & \\
Male & 14 & 46.66 \\
Female & 16 & 53.33 \\
Age & & \\
$\quad$ Younger adults (25-36 years) & 30 & 100 \\
Older adults (60+ years) & 0 & 0 \\
Education & & \\
HS diploma or less & 7 & 23.33 \\
Bachelor degree & 8 & 26.66 \\
Graduate degree & 15. & 50 \\
Employment & & \\
Students or unemployed & 3 & 10 \\
Blue-collar & 5 & 16.66 \\
White-collar & 18 & 60 \\
Self-employers & 4 & 4 \\
\hline
\end{tabular}

participant had previous knowledge, albeit only anecdotal, about the IGT.

\section{Materials}

\section{Stimuli}

Stimuli were created based exactly on the description by Ainley et al. (2013). The authors used this method to intending to influence interoceptive awareness by manipulating attention focused on narrative and bodily selves. After obtaining informed consent, the researcher explained the study and its phases and took by a smartphone a digital photograph of the participant's face with a neutral expression. This was the bodily self-conditioned stimulus. The researcher moreover asked participants to provide 6 self-relevant words, specifically their first name, their city hometown, the name of the school they recently attended, their university course, the name of their best friend, and the name of the most important person in their life at present. These words represented the stimulus of the narrative self-condition. The digital photograph was mirrorreversed in the center of the screen and autobiographical words were presented in white font on a black background, arranged in a hexagonal pattern that took up the same area of a computer screen as the picture. A black screen with a small white fixation cross $\left(1 \mathrm{~cm} \_1 \mathrm{~cm}\right)$ in the center of the computer screen was treated as a baseline condition.

\section{Task}

Bechara and colleagues (1994) to assess DM created the Iowa Gambling Task (IGT). In a laboratory context, they give 2000 fake dollars to the participant as start with the aim to maximize profit by repeatedly selecting cards from one of four decks (A, B, C, and D). Participants have 100 trials to play and each deck gives a profit or a loss. Overall, decks A and B yield on earning of $\$ 100$, on average, and large punishments, while Deck $C$ and $D$ yield an earnings of $\$ 50$, on average, and small punishments (Bechara et al., 1997). However, after 10 selections from each of the decks, participants incur a net loss, which is higher in decks A and B. Decks A and B are defined "disadvantageous" because riskier decks, instead decks $\mathrm{C}$ and $\mathrm{D}$ are considered as "advantageous". Differences between decks are related not only to long-term outcomes, but also to the number of losses vs gains ("gain frequency"). Specifically, gain frequency is high for decks A, low for decks B and D, and null for deck C (Horstmann, Villringer \& Neumann, 2012). The frequency and magnitude of gains and losses are not disclosed to participants; the ability to make better decisions is learned through the experience of sampling of rewards and punishments across decks (Bellani, Tomelleri \& Brambilla, 2009). For example, outcomes of previous choices can adjust future decisions during the task. The computerized 
version of the task is now more used; no differences have been reported with decks of paper cards (Bowman, Evans, \& Turnbull, 2005). Since its creation, it is now used as a behavioral instrument to assess risky DM as well as a clinical tool (Chiu, Huang, Duann \& Lin, 2018). Several outcomes can be measured within the task, such as total money won, total time spent, key pressing duration, the frequency of cards taken by each deck (Bolla, Eldreth, Matochik, \& Cadet, 2005). Furthermore, two variables directly associated with the DM process: the difference between total advantageous cards and total disadvantageous cards $[(\mathrm{C}+\mathrm{D})-(\mathrm{A}+\mathrm{B})]$, which is considered a global measure of advantageous DM, and the loss frequency bias or preference for decks with a low frequency of punishments (losses) $[(\mathrm{B}+\mathrm{D})-(\mathrm{A}+\mathrm{C})]$ (Besnard et al., 2015).

\section{Procedure}

Once arrived at the laboratory, participants were welcomed in a quiet room by a researcher and seated in front of the computer screen. A tablet with the IGT was put in a position below the computer screen. Firstly, the experimenter took a picture of the participant, asked for some personal information, and explained how to play the IGT following accurately the instructions by Bechara (2008). Then, the researcher turned off the light of the room and sat quietly $2 \mathrm{~m}$ behind the participant. After a brief training trial to understand how to play the IGT (15 s), participants were prompted for every three trials to keep their eyes on the computer screen for a minute for each stimulus (baseline, bodily and narrative self). Specifically, at the beginning, a small white fixation cross was placed on the computer screen to all participants (baseline condition). Then, the digital photograph previously taken (bodily stimulus) and the autobiographical words collected (autobiographical stimulus) were fixated in randomized, counterbalanced order across participants. That is, 15 participants were randomly assigned to narrative condition after baseline, with the remaining 15 participants completing the bodily condition immediately after the baseline. The assignment of each participant to the bodily or narrative condition as the first stimulus after baseline was random. At the end, the two experimental conditions (bodily and narrative stimuli) were randomly administered to all participants but in a different sequence, while the baseline was always the first condition. In general, participants were not obliged to fixate on particular aspects of the stimuli specifically; the experimenter advised them just to keep attention to the stimuli as much as possible. After each stimulus fixation, participants completed the IGT on the tablet positioned just below the computer screen. During the task, the stimuli (no stimuli, photograph, or words) were shown on the computer screen, this way filling an important part of the participants' field of view. When they finished each specific phase - baseline, bodily or narrative conditions and the Iowa
Gambling Task - a pause of 3 min was guaranteed, where the participants kept their eyes closed and rested. At the end of the overall experiment, participants were debriefed on the aim of the study and the experimenter answered their possible questions (Fig. 1).

\section{Results}

To assess Hp1, we computed the "net score" of advantageous DM [(deck C + deck D) - (deck A + deck B)] (Cassotti et al., 2014; Singh, 2016), to obtain the variable Advantageous Choices. Then repeated measures ANOVA was performed, with an experimental condition (baseline, bodily self, and narrative self) as the within-subjects factor and Advantageous Choices as the dependent variable. There was no significant effect of experimental condition on Advantageous Choices, $\mathrm{F}(2,58)=.289, p=.75, \eta^{2}=.01$, although on average more advantageous choices were made in the narrative self-focus condition $(18, \mathrm{SD}=31.02)$ as well as in the bodily self-focus condition $(17, \mathrm{SD}=34.89)$ than in the baseline condition (14.1, SD = 21.57).

To test Hp2, we computed the "net score" of loss frequency bias $[(\operatorname{deck} \mathrm{B}+\operatorname{deck} \mathrm{D})-(\operatorname{deck} \mathrm{A}+\operatorname{deck} \mathrm{C})]$, to obtain the variable Loss Frequency. Then repeated measures ANOVA was performed, with an experimental condition (baseline, bodily self, and narrative self) as the within-subjects factor and Loss Frequency as the dependent variable. There was a significant effect of experimental condition on Loss Frequency, $\mathrm{F}(2,58)=4.019, p=.02, \eta^{2}=.122$; loss frequency bias emerged in particular in the bodily-self condition (29.6, $\mathrm{SD}=16.24)$, more than in the narrative self-focus condition $(20.8, \mathrm{SD}=23.5)$ and the baseline $(19.4, \mathrm{SD}=16.24)$. Pairedsamples t-test showed that the difference was significant both in the bodily-self vs. narrative-self comparison $(t=2.130$, $p=.04)$ and in the bodily-self condition vs. baseline comparison $(\mathrm{t}=-2.520, p=.01)$, while it was not in the narrative condition vs. baseline comparison $(\mathrm{t}=-.401, p=.69)$. To check for order effects on this analysis, the counterbalance order was included in the analysis (e.g., participants who were exposed to the Bodily Self condition first vs. participants who were exposed to the Narrative Self condition first): no significant effect of the stimuli presentation order was found, $\mathrm{F}(2$, 56) $=.131, p=.87, \eta^{2}=.005$.

To test Hp3, both Advantageous Choices and Loss Frequency Bias scores from the three experimental conditions were analyzed in six independent samples t-tests by sex to assess differences between males and females (see Table 2). No significant differences emerged. Males and females' scores were not significantly different in any other variable of the study (see Table 2), except for Total Gains in the bodily-self condition, with males gaining significantly more than females $(t=2.075, p=.047)$. Moreover, two mixed- 


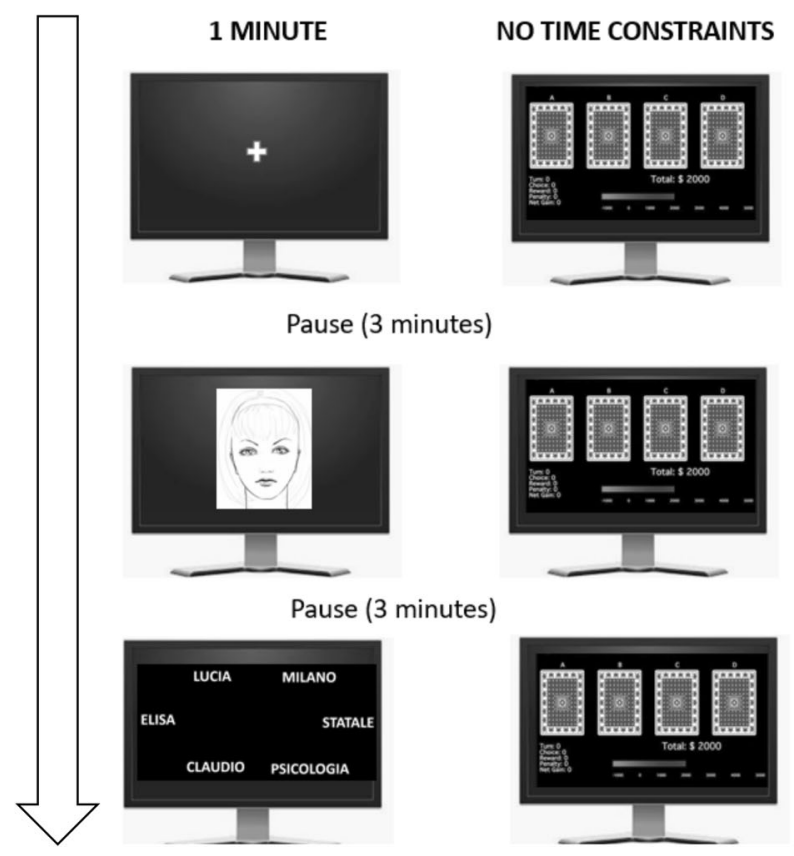

Fig. 1 A schematic representation of the experimental procedure

design ANOVAs were conducted to analyze possible interaction effects between sex and the experimental conditions, with Advantageous Choices and Loss Frequency as dependent variables. Mixed Design ANOVA on Advantageous Choices did not yield significant results regarding interaction effects, $\mathrm{F}(2,27)=1.487, p=.244, \eta^{2}=.099$; also the Mixed Design ANOVA on Loss Frequency did not yield significant results regarding interaction effects $\mathrm{F}(2,27)=2.326, p=.117$, $\eta^{2}=.147$.

To test Hp4, repeated measures ANOVAs have been conducted to analyze differences in Total Time, Response Time, Pressing Duration and Total Gains by the three conditions (baseline, bodily self and narrative self) as the independent variable. There was a significant effect of experimental condition on Total Gains, $\mathrm{F}(2,28)=2.476, p=.045, \eta^{2}=.199$; total gains differences emerged in particular in the bodilyself condition $(2244.1, \mathrm{SD}=1160)$ and in the narrative selffocus condition (2221, SD =1047.4) than in the baseline (1719.1, SD =664.5). Paired-samples t-test showed that the difference was significant both in the bodily-self vs. baseline comparison $(\mathrm{t}=-2.417, p=.022)$ and in the narrative-self condition vs. baseline comparison $(\mathrm{t}=-2.398, \mathrm{p}=.02)$, while it was not in the bodily-self condition vs. narrative-self condition $(\mathrm{t}=.123, p=.903)$.

There was a significant effect of experimental condition on Response Time, $\mathrm{F}(2,28)=11.985, p=.00, \eta 2=.461$; response time differences emerged in particular in the bodilyself condition $(1206.2, \mathrm{SD}=547.6)$ and in the narrative selffocus condition $(1214.1, \mathrm{SD}=439.1)$ than in the baseline $(1540.3, \mathrm{SD}=455.5)$. Paired-samples t-test showed that

Table 2 Average and standard deviations of both advantageous choices, loss frequency bias, total gains, response time, pressing duration and total time across baseline, bodily self and narrative self-conditions by sex

\begin{tabular}{|c|c|c|c|c|c|c|c|c|c|c|c|c|}
\hline & \multicolumn{2}{|c|}{ Advantageous choices } & \multicolumn{2}{|c|}{ Loss frequency } & \multicolumn{2}{|c|}{ Total gains } & \multicolumn{2}{|c|}{ Response time } & \multicolumn{2}{|c|}{ Pressing duration } & \multicolumn{2}{|c|}{ Total time } \\
\hline & M & SD & M & SD & M & $\mathrm{SD}$ & M & SD & M & $\mathrm{SD}$ & M & $\mathrm{SD}$ \\
\hline M & 12.4 & 15.7 & 19.8 & 15.1 & 1564.2 & 376.8 & 1527.9 & 406.2 & 106.1 & 14.9 & 147.5 & 40.3 \\
\hline $\begin{array}{l}\text { BASELINE } \\
\text { F }\end{array}$ & 15.6. & 26 & 19 & 17.6 & 1854.6 & 829.9 & 1551.1 & 507.8 & 101.3 & 23.7 & 151.3 & 49.3 \\
\hline M & 25.8 & 40.4 & 37.8 & 28.5 & $2689.2 *$ & 1250 & 1063.8 & 366.5 & 115.1 & 25.9 & 103.5 & 36.5 \\
\hline $\begin{array}{l}\text { BODILY-SELF } \\
\text { F }\end{array}$ & 9.25 & 28.2 & 22.3 & 21.8 & $1854.6^{*}$ & 949 & 1330.8 & 654 & 117.6 & 30.8 & 123.1 & 53.2 \\
\hline M & 18.8 & 38.6 & 27.4 & 25.7 & 2491 & 1313.1 & 1113.2 & 299.9 & 109.2 & 25.6 & 109.2 & 30.7 \\
\hline $\begin{array}{l}\text { NARRATIVE-SELF } \\
\text { F }\end{array}$ & 18.7 & 23.8 & 15 & 20.4 & 1984.6 & 706.5 & 1302.4 & 526.5 & 115.9 & 32 & 129.5 & 49 \\
\hline
\end{tabular}

$* p<.05$ 
participants took less time to make choices on average in bodily self e narrative self than in baseline $(t=3.135$, $p=.00 ; \mathrm{t}=4.982, \mathrm{p}=.00)$, while it was not in the bodily-self condition vs. narrative-self condition $(\mathrm{t}=-.097, p=.923)$. There was a significant effect of experimental condition on Pressing Duration, $\mathrm{F}(2,28)=5.818, p=.00$, $\eta 2=.832$; pressing duration differences emerged in particular in the bodilyself condition $(116.48, \mathrm{DS}=28.2)$ and in the narrative selffocus condition $(112.7, \mathrm{SD}=28.9)$ than in the baseline $(103.5$, $\mathrm{SD}=19.9)$. Paired-samples t-test evidenced that participants show less Pressing Duration to make choices on average in bodily self e narrative self than baseline $(t=-3.454, p=.00$; $\mathrm{t}=-2.048, p=.05)$, while it was not in the bodily-self condition vs. narrative-self condition $(\mathrm{t}=.899, p=.376)$. There was a significant effect of experimental condition on Total Time, $\mathrm{F}(2,28)=11.465, \mathrm{p}=.00, \eta 2=.450 ;$ total time differences emerged in particular in the bodily-self condition (114, $\mathrm{SD}=45.5)$ and in the narrative self-focus condition (120, $\mathrm{SD}=42)$ than in the baseline $(149.53, \mathrm{SD}=44.6)$. Pairedsamples t-test showed that participants took less Total Time to make choices on average in bodily self e narrative self than baseline $(\mathrm{t}=3.894, \mathrm{p}=.00 ; \mathrm{t}=4.567, \mathrm{p}=.00)$, while it was not in the bodily-self condition vs. narrative-self condition $(\mathrm{t}=$ $-.770, p=.447)$.

\section{Discussion}

This study explored the possibility to influence DM by promoting self-focused attention on their bodily and narrative selves. As showed by Werner and colleagues (2009), people with high self-focus attention make better decisions in a task such as the Iowa Gambling, because they are more responsive to internal sensations (e.g., anxiety) that can signal risks or opportunities. Ainley and colleagues (2013) showed that interoception could be manipulated by experimentally priming self-focused attention: both when counting their own heartbeats in front of a picture of themselves (bodily selffocused attention) or personally-relevant words (narrative self-focused attention), participants were more accurate than in baseline condition without any kind of stimulation. Basing on this literature, the present study replicated the experimental setting but with the IGT in the place of the interoception task to analyze the possible effect of self-focused attention on DM. No significant differences emerged between the three conditions regarding advantageous choices: this contradicts $\mathrm{Hp} 1$ and seems to argue against the idea that self-focused attention may improve the quality of decisions, at least in the traditional conception of the IGT (i.e., C and D decks are the advantageous ones in terms of long-term outcomes). Empirical findings showed that higher dispositional self-focused attention influences negative affects (e.g., depression and anxiety) leading to maladaptive processing routines that contribute to stress vulnerability and problem resistance (Bahrami, Kasaei \& Zamani, 2012; Gröpel, 2016; Pena \& Losada, 2017). Indeed, we argue that the manipulation of self-representations could affect individuals with high self-focused attention especially due to their tendency to reflect on their self and sensations.

In line with $\mathrm{Hp} 2$, participants preferred decks with low loss frequency in the bodily self-focus condition compared with the others. We propose two possible interpretations of this result. As hinted at in $\mathrm{Hp} 2$ as originally formulated, it is possible that primed self-focus acted as a distractor for participants, partially hindering their DM process so that they were less able to decide in favor of long-term outcomes. It is important to notice that participants in this condition looked at a picture of themselves, which according to research in other fields (i.e., reaction to selfies) could be an emotionally intense stimulus because related to the evaluation of one's appearance and social judgment (Shin, Kim, Im, \& Chong, 2017). A study by Hotton and colleagues (2019) reported that distractions affect decision making due to the increment of higher performance anxiety. One less parsimonious yet interesting interpretation would be related to the actual priming of bodily-self focus. As previously said, self-focused attention has been shown impacting DM because it allows individuals to be more responsive to internal sensations associated with the evaluation of alternatives (Werner et al., 2009). Since the effect appeared only in the condition priming focus on bodily selfrepresentation, it is possible that it made participants more sensitive to internal cues, for example, feelings of anxiety and discomfort related to punishment. For this reason, when participants were primed to pay attention to their bodily selfrepresentation, they were keen to avoid frequent punishments/ losses instead of pursuing long-term outcomes. In this regard, Sokol-Hessner and colleagues (2013) evidenced that the perception of bodily states and their intensity as choice-relevant emotional signals may magnify the relative weight related to losses over decisions under risk. Moreover, loss aversion is related to the immediate experience of realized losses or wins without long-term emotional consequences if the experience of losses has not significant lasting consequences (such as small size) or its impact may be diluted by time. Loss aversion is more strongly connected to behaviors when expected value representations are corrupted by the tendency to persevere (Worthy, Pang \& Byrne, 2013). Moreover, positive state moods have been correlated to higher reactivity (e.g., increased loss aversion); IGT indeed relies more on affective DM ("hot" processes) than calculated decisions ("cold" processes) with the frequency losses' role (Bechara, 2008). Such interpretation is interesting because loss aversion is mainly regarded as a stable trait (Sokol-Hessner \& Rutledge, 2019), while in this study it appears influenced by experimental stimuli and related participants affective mood. Finally, considering the Perceptual Accuracy Hypothesis by Silvia and Gendolla (2001), one' self-focused attention stimulates 
emotions like shame which may directly increase the tendency to avoid big losses. If self-focused attention enhances awareness of internal sensations, focusing on appearance can subsequently lead to body shame and dissatisfaction (Moradi \& Huang, 2008) as a result of the self-objectification phenomenon. For example, literature evidenced that people made temporarily aware of their appearance perform worse on various tasks such as math ones (Fredrickson, Roberts, Noll, Quinn \& Twenge, 1998) and showed more attentional interference in a Stroop task (Quinn, Kallen, Twenge \& Fredrickson, 2006). In our opinion these interpretations are not mutually exclusive, possibly both effects concurred in generating loss frequency bias in the bodily self-priming condition.

Furthermore, in contrast with $\mathrm{Hp} 3$, the present study did not observe effects of sex, besides males obtained more final gains compared to women, which is consistent with the study by Singh (2016) on the IGT. Since the brain lateralization is defined as an asymmetrical engagement of the two hemispheres, IGT shows the most prominent sex-differences in lateralization (Bolla, Eldreth, Matochik \& Cadet, 2004). Further, neuropsychological studies affirmed that the right hemisphere is more involved than the left in advantageous choices (Buelow \& Suhr, 2009). Considering that males tend to show greater functional right-lateralization of cognitive control whereas females show activation in the left hemisphere predominantly (Bolla et al., 2004; Huster, Westerhausen, Kreuder, Schweiger \& Wittling, 2009), advantageous IGT decisions and task performance reflect differences in lateralized cognitive control (Singh, 2016). However, given the relatively high effect sizes of the results, it is not possible to completely rule out Type II error, so that further studies with bigger samples might find a significant interaction with sex.

Moreover, findings show there was not mere learning effect (e.g., participants did not perform better in the two experimental conditions because of the mere repetition of the IGT). This confirms that task repetition does not always generate the learning effect (Icellioglu, 2015). At the same time, analyses showed that the randomized and counterbalanced stimuli did not generate effects of order (i.e., narrative or bodily condition as first after baseline did not affect participants' performance). These results are in accordance with Wolff and colleagues (2019) who affirmed that self-control aiming at regulating dominant impulses and behavioral tendencies do not always work effectively during tasks. Individuals rely on global and limited resources (such as emotion and attention regulations), which cannot be immediately replenished and impair on their capability of self-control.

Hp4 is partially confirmed with response time, total gains, time of completion, and pressing duration being influenced by the main independent variable: however, all of these results just show differences between the baseline and the two experimental conditions. Since specific influences of the two experimental manipulations did not emerge, these results should probably just be interpreted as signs of a general learning effect: while participants did not make choices that are more advantageous in the experimental conditions, they became faster due to the repetition of the task and training.

\section{Conclusions}

Our study corroborates the idea that self-representations and self-focused attention influence DM, at least in terms of loss aversion, and it contributes to the understanding of how internal sensations and representations play a role in selecting between alternatives. The result is interesting especially because within-subjects manipulation of loss aversion is scarce in the literature; on the contrary, loss aversion is usually recognized as a stable trait (Sokol-Hessner \& Rutledge, 2019). We proposed an alternative interpretation of the result and took into consideration that loss frequency bias could have been influenced by the emotionally intense stimulus (picture of one's face) and so caused by distraction; however, the absence of measures of interoception as used by Ainley and colleagues (2013) is a limitation of this study. We tried to avoid task overload (e.g., asking participants to perform the IGT and heartbeat perception at the same time) to focus on the former as the main hypothesis, but future studies may employ other measurement tools to analyze whether effects on cognitive tasks are related to variations in interoception. Another limitation is related to the small sample size that may underestimate the results. Furthermore, it could be interesting better understand how individual factors (e.g., age) and context variables affect IGT performance when self-focused attention is manipulated. Referring to individual characteristics, literature reported that atypical sensitivity to reward or punishment (e.g., hypersensitivity to reward, hyposensitivity to punishment, or myopia for the future, that is the insensitivity to delayed or infrequent events, whether they be rewards or punishers) explain a poor IGT performance (Bechara, Dolan \& Hindes, 2002; Bull, Tippett \& Addis, 2015). Also, since selffocused attention is associated with internal and external stimuli (Kronrod \& Ackerman, 2019; Tomita, Minamide \& Kumano, 2020), it is possible that they cannot be involved in an experimental setting. Future research could replicate this study in a natural environment as well as with a crosssectional model to assess differences in time development. Moreover, ANCOVA models could be applied to assess the influence of individual and context differences as covariates.

Furthermore, this study does not explore personality and mood variables that may affect task performance (Shukla, Rasmussen \& Nestor, 2019). Additional research is needed to measure how personality traits and mood states affect IGT performance in individuals with high self-focused attention. Moreover, although IGT is one of the main instruments to assess decision-making processes, current contributions 
questioned its reliability and validity (Schmitz, KuninaHabenicht, Hildebrandt, Oberauer \& Wilhelm, 2020). This could be solved by replicating the present design with different DM tasks, as well as other techniques for priming multiple self-representations, taking into consideration the possible influence of emotions associated with one's image. For example, the Balloon Analogue Risk Task (BART), a computer based-task that provides behavioral measures of risk-taking, could be applied as a reliable instrument to assess decisions in people who are strongly impacted by interoceptive sensations (e.g., individuals with drug additions and gambling) (Noël et al., 2013; Verdejo-Garcia, Clark \& Dunn, 2012). This could also explore whether loss aversion' manipulation can be guided by one's attention towards internal sensations, that is another lack of the present study. Additionally, to assess if the bodily stimulus (e.g., seeing one's face) is a distractor, the present experimental study could be replicated in contexts different from an experimental laboratory (e.g., ecological setting) and with various stimuli. For example, showing unfamiliar faces of other people may be helpful to assess whether faces are distracting stimuli in themselves and to what extent, independently of any reference to the self. On the contrary, if future evidences will corroborate the idea that seeing one's face influences decisions and behavior by improving selfawareness, bodily self-related stimuli may be employed within psychological interventions to promote healthy choices.

Acknowledgments Valeria Sebri is a $\mathrm{PhD}$ student within the European School of Molecular Medicine (SEMM).

Authors' Contribution Conceptualization: Valeria Sebri; Methodology: Valeria Sebri, Stefano Triberti; Formal analysis and investigation: Valeria Sebri, Stefano Triberti; Writing - original draft preparation: Valeria Sebri; Writing - review and editing: Valeria Sebri, Stefano Triberti, and Gabriella Pravettoni; Supervision: Gabriella Pravettoni.

Data Availability Data archiving is not mandated but data will be made available on reasonable request.

Code Availability Not applicable.

\section{Declarations}

Conflict of Interest The authors declare no conflicts of interest.

Open Access This article is licensed under a Creative Commons Attribution 4.0 International License, which permits use, sharing, adaptation, distribution and reproduction in any medium or format, as long as you give appropriate credit to the original author(s) and the source, provide a link to the Creative Commons licence, and indicate if changes were made. The images or other third party material in this article are included in the article's Creative Commons licence, unless indicated otherwise in a credit line to the material. If material is not included in the article's Creative Commons licence and your intended use is not permitted by statutory regulation or exceeds the permitted use, you will need to obtain permission directly from the copyright holder. To view a copy of this licence, visit http://creativecommons.org/licenses/by/4.0/.

\section{References}

Ainley, V., Maister, L., Brokfeld, J., Farmer, H., \& Tsakiris, M. (2013). More of myself: Manipulating interoceptive awareness by heightened attention to bodily and narrative aspects of the self. Consciousness and Cognition, 22(4), 1231-1238. https://doi.org/ 10.1016/j.concog.2013.08.004.

Araujo, H. F., Kaplan, J., Damasio, H., \& Damasio, A. (2015). Neural correlates of different self domains. Brain and Behavior, 5(12), e00409. https://doi.org/10.1002/brb3.409.

Bahrami, F., Kasaei, R., \& Zamani, A. (2012). Preventing worry and rumination by induced positive emotion. International Journal of Preventive Medicine, 3(2), 102.

Baumeister, R. F. (1984). Choking under pressure : Self-consciousness and paradoxical effects of incentives on skillful performance. Journal of Personality and Social Psychology, 46(3), 610-620. https://doi.org/10.1037/0022-3514.46.3.610.

Bechara, A. (2008). Iowa gambling task professional manual. Lutz: Psychological Assessment Resources.

Bechara, A., Damasio, A. R., Damasio, H., \& \& Anderson, S. W. (1994). Insensitivity to future consequences following damage to human prefrontal cortex. Cognition, 50(1-3), 7-15.

Bechara, A., Damasio, H., Tranel, D., \& Damasio, A. R. (1997). Deciding advantageously before knowing the advantageous strategy. Science, 275(5304), 1293-1295. http://doi.org/. https://doi.org/10.1126/ science.275.5304.1293.

Bechara, A., Dolan, S., \& Hindes, A. (2002). Decision-making and addiction (part II): myopia for the future or hypersensitivity to reward? Neuropsychologia, 40(10), 1690-1705. https://doi.org/10.1016/ S0028-3932(02)00016-7.

Beitz, K. M., Salthouse, T. A., \& Davis, H. P. (2014). Performance on the Iowa Gambling Task: From 5 to 89 years of age. Journal of Experimental Psychology: General, 143(4), 1677.

Bellani, M., Tomelleri, L., \& Brambilla, P. (2009). Emotion-based decision making in schizophrenia: evidence from the Iowa Gambling Task. Epidemiology and Psychiatric Sciences, 18(2), 104-106. https://doi.org/10.1017/S1121189X0000097X.

Bermúdez, J. L. (2011). Bodily awareness and self-consciousness. In S. Gallagher (Ed.), The Oxford Handbook of the Self (pp. 1-39). Oxford: Oxford University Press.

Besnard, J., Allain, P., Aubin, G., Chauviré, V., Etcharry-Bouyx, F., \& Le Gall, D. (2015). Decision-making of prefrontal patients with the Iowa Gambling Task: Unexpected spared performances and preliminary evidence for the need of alternative measures. Clinical Neuropsychologist, 29(4), 509-521. https://doi.org/10.1080/ 13854046.2015 .1050458

Blanke, O. (2012). Multisensory brain mechanisms of bodily self-consciousness. Nature Reviews Neuroscience, 13(8), 556. https://doi. org/10.1038/nrn3292.

Bolla, K. I., Eldreth, D. A., Matochik, J. A., \& Cadet, J. L. (2004). Sexrelated differences in a gambling task and its neurological correlates. Cerebral cortex, 14(11), 1226-1232. https://doi.org/10.1093/cercor/ bhh083.

Bolla, K. I., Eldreth, D. A., Matochik, J. A., \& \& Cadet, J. L. (2005). Neural substrates of faulty decision-making in abstinent marijuana users. Neuroimage, 26, 480-492. https://doi.org/10.1016/j. neuroimage.2005.02.012

Bowman, C. H., Evans, C. E. Y., \& \& Turnbull, O. H. (2005). Artificial time constraints on the Iowa gambling task: the effects of behavioural performance and subjective experience. Brain and Cognition, 57, 21-25. https://doi.org/10.1016/j.bandc.2004.08.015

Brown, E. C., Hack, S. M., Gold, J. M., Carpenter Jr., W. T., Fischer, B. A., Prentice, K. P., \& Waltz, J. A. (2015). Integrating frequency and magnitude information in decision- making in schizophrenia: An account of patient performance on the Iowa Gambling Task. 
Journal of Psychiatric Research, 66, 16-23. https://doi.org/10.1007/ 978-3-540-68706-1 853.

Buelow, M. T., \& Suhr, J. A. (2009). Construct validity of the Iowa gambling task. Neuropsychology review, 19(1), 102-114. https:// doi.org/10.1007/s11065-009-9083-4.

Bull, P. N., Tippett, L. J., \& Addis, D. R. (2015). Decision making in healthy participants on the Iowa Gambling Task: new insights from an operant approach. Frontiers in Psychology, 6, 391. https://doi. org/10.3389/fpsyg.2015.00391.

Cassotti, M., Aïte, A., Osmont, A., Houdé, O., Borst, G., \& Toplak, M. E. (2014). What have we learned about the processes involved in the Iowa Gambling Task from developmental studies? Frontiers in Psychology, 5, 1-5. https://doi.org/10.3389/fpsyg.2014.00915.

Charness, G., \& Gneezy, U. (2012). Strong evidence for gender differences in risk taking. Journal of Economic Behavior \& Organization, 83(1), 50-58. https://doi.org/10.1016/j.jebo.2011.06.007.

Chiu, Y. C., Huang, J. T., Duann, J. R., \& \& Lin, C. H. (2018). Twenty years after the iowa gambling task: rationality, emotion, and decision-making. Frontiers in Psychology, 8, 2353. https://doi.org/10. 3389/fpsyg.2017.02353

Choi, H. S., Cho, S. J., Seo, J. G., \& Bechtoldt, M. N. (2018). The joint impact of collectivistic value orientation and independent selfrepresentation on group creativity. Group Processes \& Intergroup Relations, 21(1),37-56. https://doi.org/10.1177/ 1368430216638539.

Christoff, K., Legrand, D., Cosmelli, D., \& Thompson, E. (2011). Specifying the self for cognitive neuroscience. Trends in Cognitive Sciences, 15(3), 104-112. https://doi.org/10.1016/j.tics.2011.01. 001.

Damasio, A. R. (2010). Self comes to mind: Constructing the conscious brain. London: Vintage.

De Martino, B., Camerer, C. F., \& Adolphs, R. (2010). Amygdala damage eliminates monetary loss aversion. Proceedings of the National Academy of Sciences USA, 107, 3788-3792.

Di Lernia, D., Cipresso, P., Pedroli, E., \& Riva, G. (2018). Toward an embodied medicine: A portable device with programmable interoceptive stimulation for heart rate variability enhancement. Sensors (Switzerland), 18(8). https://doi.org/10.3390/s18082469.

Dominey, P. F., Paléologue, V., Pandey, A. K., \& Ventre-Dominey, J. (2017, September). Improving quality of life with a narrative companion. In 2017 26th IEEE International Symposium on Robot and Human Interactive Communication (RO-MAN) (pp. 127-134). IEEE.

Dunn, B. D., Galton, H. C., Morgan, R., Evans, D., Oliver, C., Meyer, M., ...Dalgleish, T. (2010). Listening to your heart: How interoception shapes emotion experience and intuitive decision making. Psychological Science, 21(12), 1835-1844. https://doi.org/10. $1177 / 0956797610389191$

Faul, F., Erdfelder, E., Lang, A. G., \& Buchner, A. (2007). GPower 3: A flexible statistical power analysis program for the social, behavioral, and biomedical sciences. Behavior Research Methods, 39, 175-191.

Frassinetti, F., Ferri, F., Maini, M., Benassi, M. G., \& \& Gallese, V. (2011). Bodily self: an implicit knowledge of what is explicitly unknown. Experimental Brain Research, 212(1)), 153-160. https://doi.org/10.1007/s00221-011-2708-x

Fredrickson, B. L., Roberts, T., Noll, S. M., Quinn, D. M., \& Twenge, J. M. (1998). That swimsuit becomes you: Sex differences in selfobjectification, restrained eating, and math performance. Journal of Personality and Social Psychology, 75, 269-284. https://doi. org/10.1037/0022-3514.75.1.269.

Gal, D., \& Rucker, D. D. (2018). The loss of loss aversion: Will it loom larger than its gain? Journal of Consumer Psychology, 28(3), 497516. https://doi.org/10.1002/jcpy.1047.
Gröpel, P. (2016). Self-focused attention and motor skill failure: The moderating role of action orientation. Sport, Exercise, and Performance Psychology, 5(3), 206.

Higgins, E. T. (1987). Self-discrepancy: A theory relating self and affect. Psychological Review, 94(3), 319-340. https://doi.org/10.1037/ 0033-295X.94.3.319.

Horstmann, A., Villringer, A., \& Neumann, J. (2012). Iowa Gambling Task: There is more to consider than long-term outcome. Using a linear equation model to disentangle the impact of outcome and frequency of gains and losses. Frontiers in Neuroscience, 6, 61. https://doi.org/10.3389/fnins.2012.00061.

Hotton, M. T., Miller, R., \& Chan, J. K. K. (2019). Performance anxiety among surgeons. The Bulletin of the Royal College of Surgeons of England, 101(1), 20-26. https://doi.org/10.1308/rcsbull.2019.20.

Huster, R. J., Westerhausen, R., Kreuder, F., Schweiger, E., \& Wittling, W. (2009). Hemispheric and gender related differences in the midcingulum bundle: a DTI study. Human brain mapping, 30(2), 383-391. https://doi.org/10.1002/hbm.20509.

Icellioglu, S. (2015). Iowa Gambling Test: normative data and correlation with executive functions. Dusunen Adam The Journal of Psychiatry and Neurological Sciences, 28(3), 222. https://doi.org/10.5350/ DAJPN2015280305.

James, W. (2011). The consciousness of self. Journal of Cosmology, 14(1).

Jamison, J., \& Wegener, J. (2010). Multiple selves in intertemporal choice. Journal of Economic Psychology, 31(5), 832-839. https:// doi.org/10.1016/j.joep.2010.03.004.

Johnson, J. E. V., \& Powell, P. L. (1994). Decision making, risk and gender: Are managers different? British Journal of Management, 5(2), 123-138. https://doi.org/10.1111/j.1467-8551.1994.tb00073.

Kronrod, A., \& Ackerman, J. M. (2019). I'm so touched! Self-touch increases attitude extremity via self-focused attention. Acta psychologica, 195, 12-21. https://doi.org/10.1016/j.actpsy.2019. 02.005 .

Legrand, D. (2006). The bodily self: The sensori-motor roots of prereflective self-consciousness. Phenomenology and the Cognitive Sciences, 5(1), 89-118. https://doi.org/10.1007/s11097-005-90156

Mancha, R. M., \& Yoder, C. Y. (2015). Cultural antecedents of green behavioral intent: An environmental theory of planned behavior. Journal of Environmental Psychology, 43, 145-154. https://doi. org/10.1016/j.jenvp.2015.06.005.

Markus, H., \& Kunda, Z. (1986). Stability and malleability of the selfconcept. Journal of Personality and Social Psychology, 51(4), 858866. https://doi.org/10.1037/0022-3514.51.4.858.

Markus, H., Smith, J., \& Moreland, R. L. (1985). Role of the self-concept in the perception of others. Journal of Personality and Social Psychology, 49, 1494-1512.

McConnell, A. R., Shoda, T. M., \& Skulborstad, H. M. (2012). The self as a collection of multiple self-aspects: Structure, development, operation, and implications. Social Cognition, 30(4), 380-395. https:// doi.org/10.1521/soco.2012.30.4.380.

Merrill, N., Waters, T. E., \& Fivush, R. (2016). Connecting the self to traumatic and positive events: Links to identity and well-being. Memory, 24(10), 1321-1328. https://doi.org/10.1080/09658211. 2015.1104358

Moradi, B., \& Huang, Y. (2008). Objectification theory and psychology of women: A decade of advances and future directions. Psychology of Women Quarterly, 32, 377-398. https://doi.org/10.1111/j.14716402.2008.00452.x. 
Noël, X., Brevers, D., \& Bechara, A. (2013). A triadic neurocognitive approach to addiction for clinical interventions. Frontiers in Psychiatry, 4, 179.

Northoff, G. (2007). Psychopathology and pathophysiology of the self in depression - neuropsychiatric hypothesis. Journal of Affective Disorders, 104(1-3), 1-14. https://doi.org/10.1016/j.jad.2007.02. 012.

Pena, M., \& Losada, L. (2017). Test anxiety in spanish adolescents: examining the role of emotional attention, and ruminative selffocus and regulation. Frontiers in Psychology, 8, 1423. https://doi. org/10.3389/fpsyg.2017.01423.

Piff, P. K., Dietze, P., Feinberg, M., Stancato, D. M., \& Keltner, D. (2015). Awe, the small self, and prosocial behavior. Journal of personality and social psychology, 108(6), 883. https://doi.org/10. 1037/pspi0000018.

Ploner, M., \& Regner, T. (2013). Journal of economic behavior \& organization self-image and moral balancing: An experimental analysis. Journal of Economic Behavior and Organization, 93, 374-383. https://doi.org/10.1016/j.jebo.2013.03.030.

Price, T. F., \& Harmon-Jones, E. (2015). Embodied emotion: The influence of manipulated facial and bodily states on emotive responses. Wiley Interdisciplinary Reviews: Cognitive Science, 6(6), 461-473. https://doi.org/10.1002/wcs.1370.

Quinn, D. M., Kallen, R. W., Twenge, J. M., \& Fredrickson, B. L. (2006). The disruptive effect of self-objectification on performance. Psychology of Women Quarterly, 30, 59-64. https://doi.org/10. 1111/j.1471-6402.2006.00262.x.

Riesmeyer, C., Hauswald, J., \& Mergen, M. (2019). (Un) Healthy behavior? The relationship between media literacy, nutritional behavior, and self-representation on instagram. Media and Communication, 7(2), 160-168. https://doi.org/10.17645/mac.v7i2.1871.

Roelofsma, P. H., \& Kurt, S. (2013). Using multiple self-theory of planner and doer as a virtual coaching framework for changing lifestyles: The role of expert, motivator and mentor coaches. In Human Aspects in Ambient Intelligence (pp. 107-120). Atlantis Press, Paris.

Salomon, R., Noel, J. P., Łukowska, M., Faivre, N., Metzinger, T., Serino, A., \& Blanke, O. (2017). Unconscious integration of multisensory bodily inputs in the peripersonal space shapes bodily selfconsciousness. Cognition, 166, 174-183. https://doi.org/10.1016/j. cognition.2017.05.028

Schmitz, F., Kunina-Habenicht, O., Hildebrandt, A., Oberauer, K., \& Wilhelm, O. (2020). Psychometrics of the Iowa and Berlin gambling tasks: Unresolved issues with reliability and validity for risk taking. Assessment, 27(2), 232-245.

Sebri, V., Savioni, L., Triberti, S., Durosini, I., Mazzocco, K., \& Pravettoni, G. $\left(2020^{\mathrm{b}}\right)$. Do You Transfer Your Skills? From sports to health management in cancer patients. Frontiers in Psychology, 11. https://doi.org/10.3389/fpsyg.2020.00546.

Sebri, V., Savioni, L., Triberti, S., Mazzocco, K., \& Pravettoni, G. (2019). How to train your health: Sports as a resource to improve cognitive abilities in cancer patients. Frontiers in Psychology. https://doi.org/ 10.3389/fpsyg.2019.02096.

Sebri, V., Triberti, S., \& Pravettoni, G. $\left(2020^{\mathrm{a}}\right)$. Injured self: Autobiographical memory, self-concept and mental health risk in breast cancer survivors. Frontiers in Psychology, 11, 2962. https:// doi.org/10.3389/fpsyg.2020.607514.

Shin, Y., Kim, M., Im, C., \& Chong, S. C. (2017). Selfie and self: The effect of selfies on self-esteem and social sensitivity. Personality and Individual Differences, 111, 139-145. https://doi.org/10.1016/ j.paid.2017.02.004

Shook, N. J., Delaney, R. K., Strough, J., Wilson, J. M., Sevi, B., \& Altman, N. (2019). Playing it safe: Dispositional mindfulness partially accounts for age differences in health and safety risktaking propensity. Current Psychology, 1-11.

Shukla, M., Rasmussen, E. C., \& Nestor, P. G. (2019). Emotion and decision-making: Induced mood influences IGT scores and deck selection strategies. Journal of clinical and experimental neuropsychology, 41(4), 341-352. https://doi.org/10.1080/13803395.2018. 1562049.

Silvia, P. J., \& \& Gendolla, G. H. (2001). On introspection and selfperception: Does self-focused attention enable accurate self-knowledge? Review of General Psychology, 5(3), 241-269. https://doi. org/10.1037/1089-2680.5.3.241

Singer, J. A., Blagov, P., Berry, M., \& Oost, K. M. (2013). Self-defining memories, scripts, and the life story: Narrative identity in personality and psychotherapy. Journal of Personality, 81(6), 569-582. https:// doi.org/10.1111/jopy.12005.

Singh, V. (2016). Sex-differences, handedness, and lateralization in the Iowa Gambling Task. Frontiers in Psychology, 7, 708. https://doi. org/10.3389/fpsyg.2016.00708.

Sokol-Hessner, P., Camerer, C. F., \& Phelps, E. A. (2013). Emotion regulation reduces loss aversion and decreases amygdala responses to losses. Social cognitive and affective neuroscience, 8(3), 341350. https://doi.org/10.1093/scan/nss002.

Sokol-Hessner, P., Hartley, C. A., Hamilton, J. R., \& Phelps, E. A. (2015). Interoceptive ability predicts aversion to losses. Cognition and Emotion, 29(4), 695-701. https://doi.org/10.1080/02699931. 2014.925426.

Sokol-Hessner, P., \& Rutledge, R. B. (2019). The psychological and neural basis of loss aversion. Current Directions in Psychological Science, 28(1), 20-27. https://doi.org/10.1177/0963721418806510.

Stanton, S. J., Liening, S. H., \& Schultheiss, O. C. (2011). Testosterone is positively associated with risk taking in the Iowa Gambling Task. Hormones and Behavior, 59(2), 252-256. https://doi.org/10.1016/j. yhbeh.2010.12.003.

Stevenson, J., \& Clegg, S. (2011). Possible selves: students orientating themselves towards the future through extracurricular activity. British Educational Research Journal, 37(2), 231-246. https://doi. org/10.1080/01411920903540672.

Strohminger, N., Knobe, J., \& Newman, G. (2017). The true self: A psychological concept distinct from the self. Perspectives on Psychological Science, 12(4), 551-560. https://doi.org/10.1177/ 1745691616689495 .

Sui, J., \& Humphreys, G. W. (2015). The integrative self: How selfreference integrates perception and memory. Trends in Cognitive Sciences, 19(12), 719-728. https://doi.org/10.1016/j.tics.2015.08.015.

Tajfel, H. (1974). Social identity and intergroup behavior. Social Science Information. https://doi.org/10.1177/053901847401300204.

Thagard, P., \& Wood, J. V. (2015). Eighty phenomena about the self: Representation, evaluation, regulation, and change. Frontiers in psychology, 6, 334. https://doi.org/10.3389/fpsyg.2015.00334.

Tomita, N., Minamide, A., \& Kumano, H. (2020). Neural correlates supported by eye movements of self-focused attention and otherfocused attention in social situations. Cognitive Therapy and Research, 1-15. https://doi.org/10.1007/s10608-019-10075-2

Triberti, S., Gorini, A., Savioni, L., Sebri, V., \& Pravettoni, G. (2019). Avatars and the disease: digital customization as a resource for selfperception assessment in breast cancer patients. Cyberpsychology, Behavior, and Social Networking, 22(8), 558-564. https://doi.org/ 10.1089/cyber.2018.0461.

Tversky, A., \& Kahneman, D. (1992). Advances in prospect theory: Cumulative representation of uncertainty. Journal of Risk and uncertainty, 5(4), 297-323. 
Verdejo-Garcia, A., Clark, L., \& Dunn, B. D. (2012). The role of interoception in addiction: a critical review. Neuroscience \& Biobehavioral Reviews, 36(8), 1857-1869.

Werner, N. S., Jung, K., Duschek, S., \& Schandry, R. (2009). Enhanced cardiac perception is associated with benefits in decision-making. Psychophysiology, 46(6), 1123-1129. https://doi.org/10.1111/j. 1469-8986.2009.00855.x.

Wolff, W., Sieber, V., Bieleke, M., \& Englert, C. (2019). Task duration and task order do not matter: no effect on self-control performance.
Psychological research, 1-11. https://doi.org/10.1007/s00426-01901230-1.

Worthy, D. A., Pang, B., \& Byrne, K. A. (2013). Decomposing the roles of perseveration and expected value representation in models of the Iowa gambling task. Frontiers in psychology, 4, 640. https://doi.org/ 10.3389/fpsyg.2013.00640.

Publisher's Note Springer Nature remains neutral with regard to jurisdictional claims in published maps and institutional affiliations. 